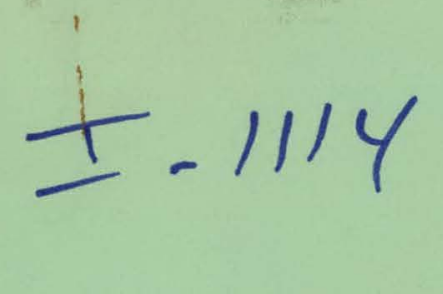

\title{
vai-1 19HASTER
}

\author{
CHARACTERIZATION OF THE DYNAMIC \\ ROADWAY-POWERED ELECTRIC-VEHICLE SYSTEM
}

\author{
J. D. Salisbury \\ D. Mullenhoff \\ C. E. Walter
}

TRANSPORTATION SYSTEMS RESEARCH

October 30,1981

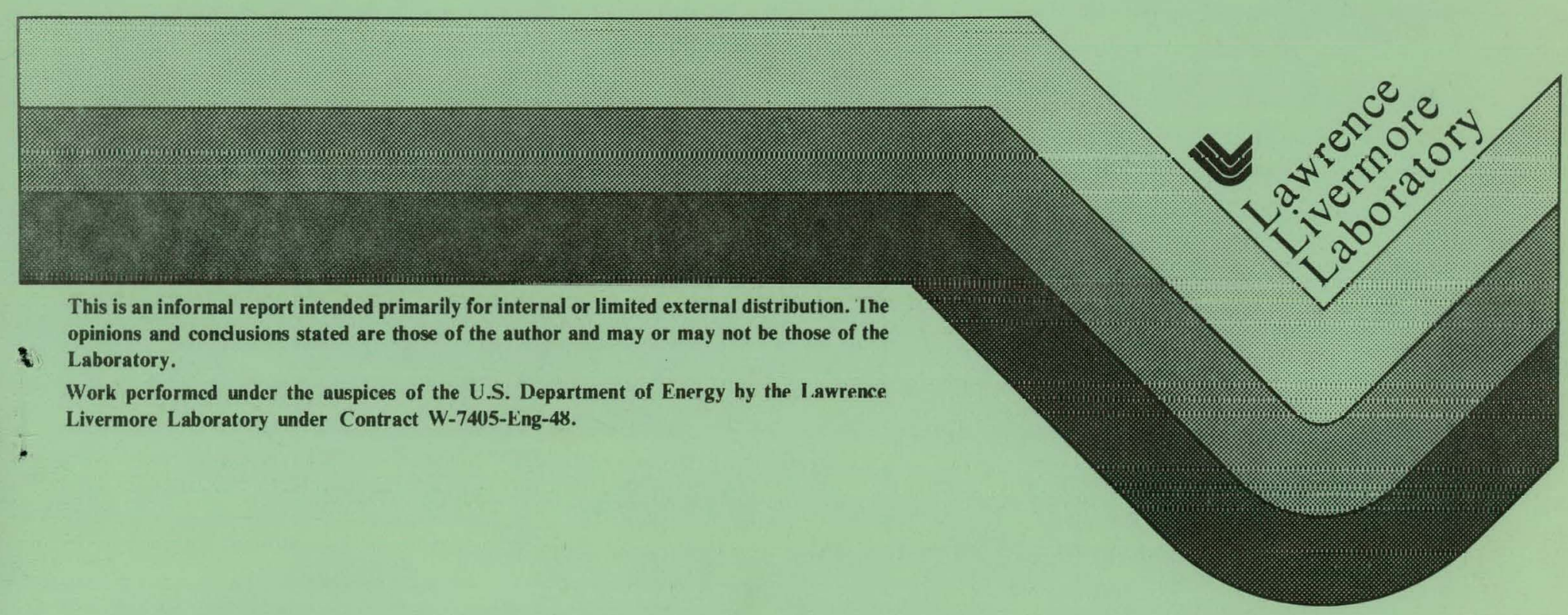




\section{DISCLAIMER}

This report was prepared as an account of work sponsored by an agency of the United States Government. Neither the United States Government nor any agency Thereof, nor any of their employees, makes any warranty, express or implied, or assumes any legal liability or responsibility for the accuracy, completeness, or usefulness of any information, apparatus, product, or process disclosed, or represents that its use would not infringe privately owned rights. Reference herein to any specific commercial product, process, or service by trade name, trademark, manufacturer, or otherwise does not necessarily constitute or imply its endorsement, recommendation, or favoring by the United States Government or any agency thereof. The views and opinions of authors expressed herein do not necessarily state or reflect those of the United States Government or any agency thereof. 


\section{DISCLAIMER}

Portions of this document may be illegible in electronic image products. Images are produced from the best available original document. 
TABLE OF CONTENTS

INTRODUCTION

UCID--19272

DE82 007149

Page

CONFIGURATION FOR ROADWAY AND PICKUP TESTS

POWER LOSSES IN THE ROADWAY 3

Stored Energy vs. Losses 3

Decomposition of the Roadway Losses $\quad$. 4

$\begin{array}{lr}\text { POWER LOSSES IN THE STATIC PICKUP } & 6\end{array}$

Stored Energy vs Losses $\quad$ · $\quad 6$

Decomposition of the Pickup Losses $\quad 6$

$\begin{array}{lc}\text { MUTUAL AND LEAKAGE INDUCTANCE } & 9\end{array}$

Mutual Inductance Determination $\quad 9$

Leakage Inductance Determination $\quad 10$

REFERENCES 12

$\begin{array}{ll}\text { INSTRUMENTS } & 13\end{array}$

$\begin{array}{ll}\text { APPENDIX } & 15\end{array}$

Description of Tests $\quad 15$

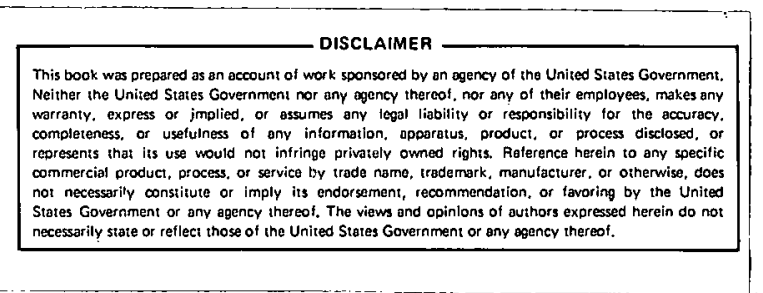

DISTRIBUTIIN OF THIS DOCUMEHT IS UNLLAITED 


\section{CHARACTERIZATION OF THE \\ DYNAMIC ROADWAY POWERED ELECTRIC VEHICLE SYSTEM}

\section{INTRODUCTION}

The measurements, data reduction, and analysis contained herein are for the most part preliminary. The instrumentation system for dynamic measurements was not completed and so the measurements taken were in the static mode and a limited amount of instruments was used.

Most of these preliminary measurements were made to characterize the losses in the roadway and the pickup of the dynamic RPEV system. By analysis of power, voltage, current and impedance-bridge measurements (at $100 \mathrm{~Hz}$ and $1000 \mathrm{~Hz}$ ), the equivalent series resistance (ESR) and equivalent parallel resistance (EPR) of the roadway and pickup inductances and capacitances were derived. Separation of the inductive and capacitive losses was difficult because of the large ratio of stored energy to power loss, that is, the " $Q$ " of each of these system elements, and the separation was accomplished by modeling the system losses and making a least-squares fit to the model with the test data. The bridge data was used primarily for capacitance and inductance values and the ESR or EPR data were not analyzed.

\section{CONFIGURATION FOR ROADWAY AND PICKUP TESTS}

For roadway power loss tests, the roadway was excited by the generator without the vehicle. This is shown in Fig. 1, and data were taken as the roadway capacitance, $\mathrm{Cl}$, was reduced in steps from resonance. The data used were primarily from Test 26 although bridge data of the capacitors were also used (capacitance only).

Figure 2 is the configuration for the pickup tests. Note that the generator has been connected to the pickup and, as in the roadway tests, the tuning capacitor, C2, was reduced in steps from resonance. Data were used from Test 29, but as with the roadway, bridge data of the capacitors were also used.

By reduoing the capacitance in the roadway and pickup, it was possible to decompose the total power loss into its separate parts. For the roadway, this gave values for the ESR (equivalent series resistance) of the inductance, $L l$, and the df (dissipation 


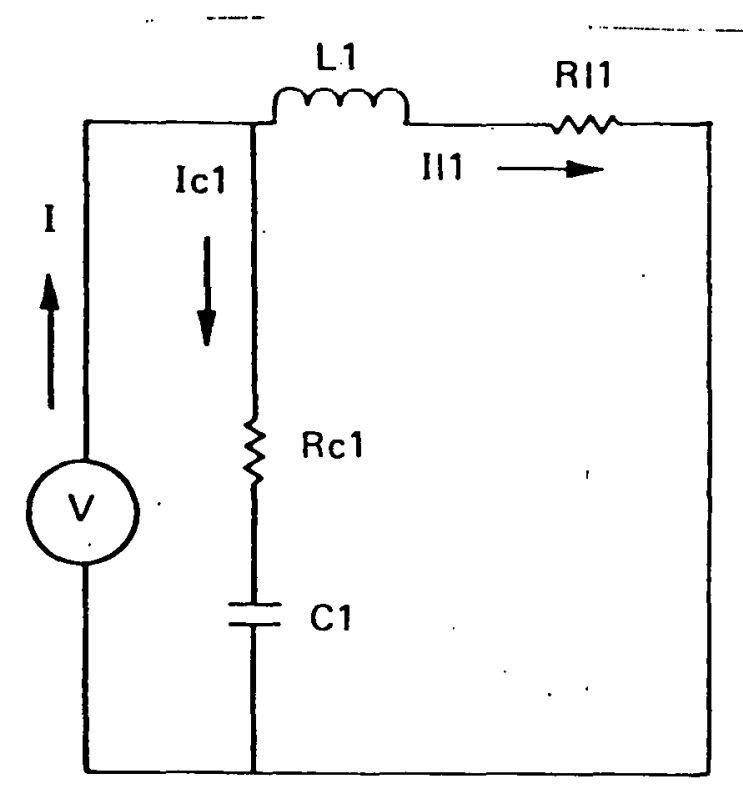

Fig. 1. Schematic of the roadway part of the dynamic RPEV system.

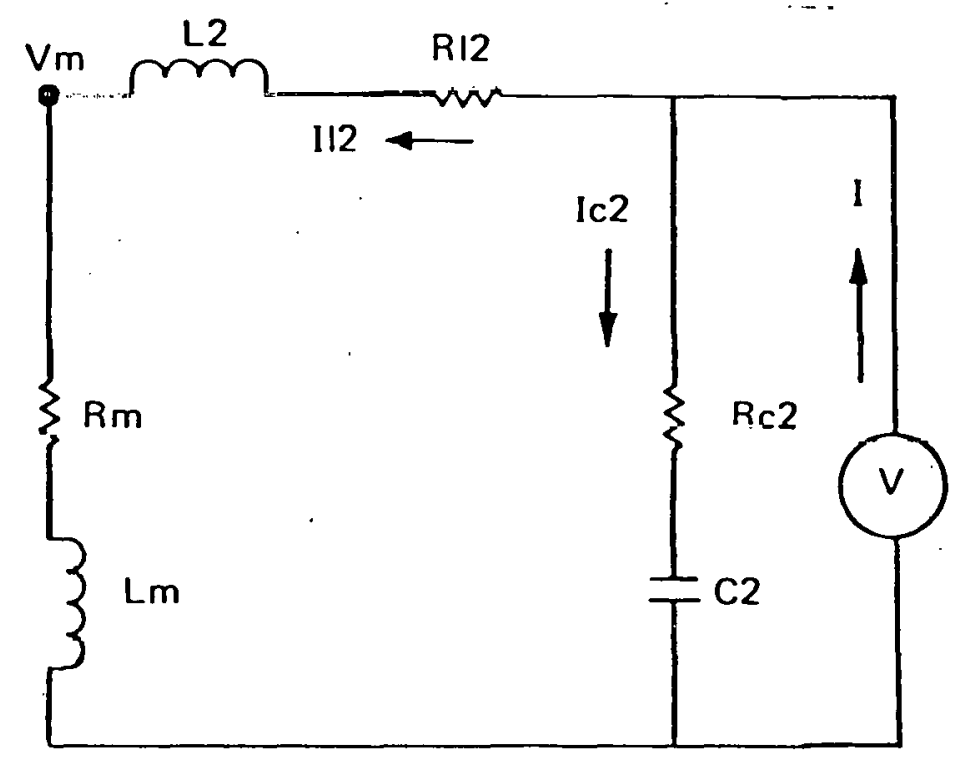

Fig. 2. Schematic of the unity-turns-ratio equivalent circuit of the pickup showing the generator connection for determining pickup losses.

factor) for the capacitor, Cl. Similarly, for the pickup the ESR for the core loss, RM, the ESR for the winding losses, RL2, and the of for the tuning capacitor, C2, were obtained. In addition, an ESR for a temporary fixed capacitance, which was necessary in order to achieve resonance with the largest air gap $(8 \mathrm{~cm})$ used, was determined. This capacitance was treated separately because of its high wiring resistance $-\mathbf{a}$ condition that would have been corrected before the tests if it had been recognized. 


\section{POWER LOSSES IN THE ROADWAY}

\section{Stored Energy vs. Losses}

For circuit elements such as those of the dynamic RPEV system, the " $Q$ " is relatively high which causes the phase angle between their voltage and current to be large (close to 90 degrees) which, in turn, defeats attempts to measure their power loss in a conventional way.

The "Q" of an electrical circuit is defined as the ratio of the peak stored energy to the average power loss per cycle. Or, put another way,

or

$$
\mathrm{Q}=2 \pi\left(\mathrm{Li}^{2}\right) / 2 \mathrm{P} / \mathrm{f}=\omega \mathrm{Li}^{2} / 2 \mathrm{P}
$$

$$
Q=\omega L / E S R
$$

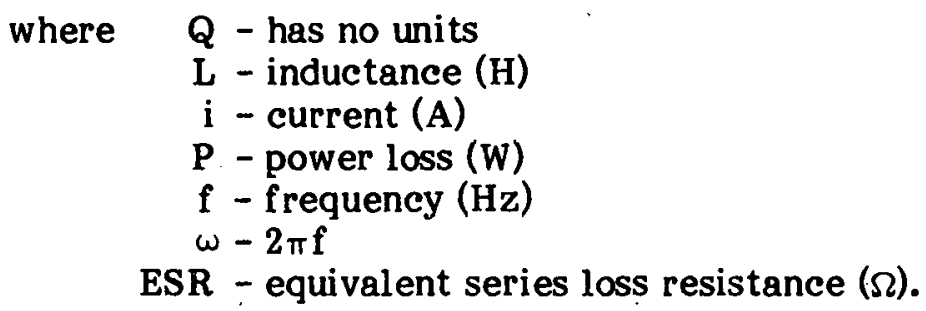

This is the expression for the $Q$ of an inductor. The $Q$ of a capacitor is also the ratio of its peak energy and losses or its reactance divided by its ESR, or

$$
Q=1 / \omega C(E S R)
$$

\section{where $1 / \omega C$ - capacitive reactance $(\Omega)$}

and the other symbols have the same meaning as above.

In general, the ESR of a capacitor or inductor is used to represent its power loss, and if more than one capacitor is used in parallel, the ESR of the parallel combination is the same as if all the ESR's were connected in parallel. This also holds for inductors if they are connected in parallel. Of course, if they are connected in series, the total ESR is just the sum of the individual ESR's. 
It is sometimes convenient to represent the loss of a component or system by its equivalent parallel resistance, EPR, and this is treated in a similar way to the ESR. If the $Q$ of a component is high, that is greater than 10, the value of the capacitor (or inductor) is not changed very much by the use of either representation of its losses. Therefore, the choice of which one to use is a matter of personal preference.

\section{Decomposition of the Roadway Losses}

Because of the relatively high $Q$ of both the inductance and capacitance of the roadway, the power loss was not measurable by the use of standard wattmeter techniques. (The RFL wattmeter cannot measure power of a circuit with a power factor of less than 5\%. The meter is designed to blank its display if this is the situation.) Instead, the roadway was tuned to near resonance and its total power loss was measured at a given road current. Then the tuning capacitance was reduced in steps until a generator current of about $190 \mathrm{~A}$ was reached (the generator was fused for $200 \mathrm{~A}$ ) and the power at each of these steps was measured. The purpose of reducing the capacitance was to determine the power loss caused by the capacitors and, from this, to infer the power loss of the roadway inductance. Thus, the equivalent loss resistance of the inductance, $\mathrm{RLl}$, can be determined and used in later analysis to define this part of the roadway losses. Furthermore, a comparison of RLl with the value used in previous analyses provides some means of evaluating the performance of this system component. Much greater losses than expected were found to be present in the roadway inductance. The reasons for this condition must be investigated so that future designs of RPEV systems can be improved. In a similar manner, the other components of the dynamic RPEV system can be examined if the losses can be decomposed into their separate parts in a reasonably accurate way.

To decompose the total loss into its two parts, the measurement data were used in a mathematical model:

$$
\mathrm{P}=\left(\mathrm{ILl}^{2}\right)(\mathrm{RLl})+\left(\mathrm{ICl}^{2}\right)(\mathrm{RCl})
$$

where $\quad P$ - power input to the roadway (W)

ILl - roadway inductor current (A)

RL1 - equivalent series loss resistance of $\mathrm{Ll}(\Omega)$

ICl - capacitor current (A)

$\mathrm{RCl}-(\mathrm{ESR}$ of $\mathrm{Cl})=\mathrm{df} / \omega \mathrm{Cl}$. 
With this model, the data were processed to find least-squares values for the coefficients $\mathrm{RLl}$ and $\mathrm{RCl}$, but the value of $\mathrm{RCl}$ was contained in the dissipation factor, df, as shown in the following section.

\section{Results}

The data for the roadway are primarily from Test 26. Figure 3 is a plot of the $\mathrm{Cl}$ values vs. power. From these data, the roadway was found to have:

$$
\begin{aligned}
\mathrm{RLl} & =3.47 \mathrm{~m} \Omega \\
\mathrm{RCl} & =\mathrm{df} / \omega \mathrm{Cl} \\
\mathrm{df} & =.0126 \\
\mathrm{f} & =283 \mathrm{~Hz}, \\
\mathrm{Cl} & =270 \mu \mathrm{F} \text { at resonance }
\end{aligned}
$$

These values were based on a least-squares fit of the data of Test 26 to the model of Eq. (4). In a previous analysis ${ }^{l}$ that was based on manufacturers' loss data, df $=.001$ and $\mathrm{RLl}=1.53 \mathrm{~m} \Omega($ at $300 \mathrm{~Hz}$ ).

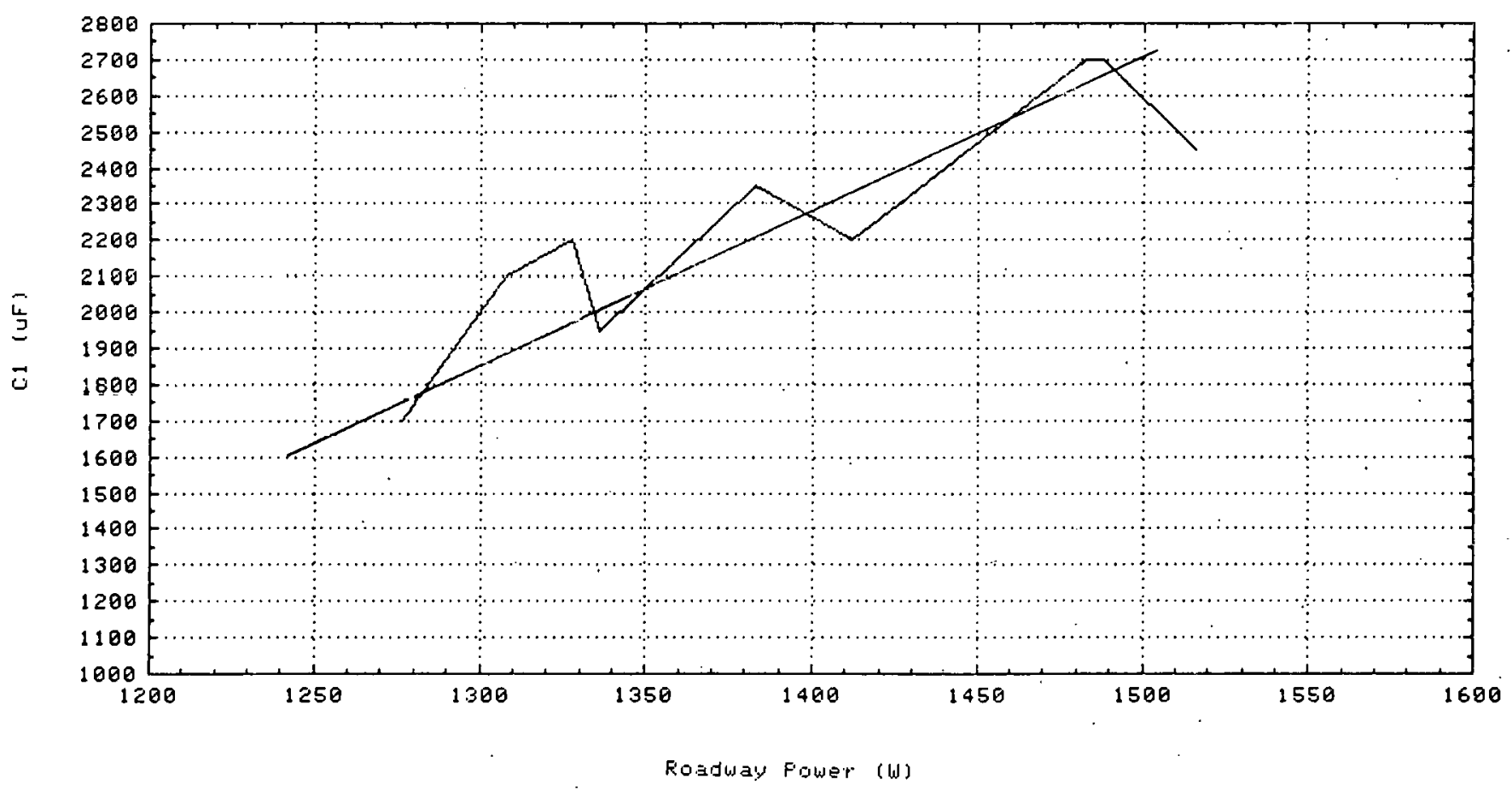

Fig. 3. Input power as a function of capacitance, $\mathrm{Cl}$, for the dynamic $\mathrm{RPEV}$ roadway without a vehicle. The current, ILl, was $500 \mathrm{~A}$ and the generator frequency was $283 \mathrm{~Hz}$. The data are from Test 26. The straight line is a least-squares fit to these datz. 
Stored Energy vs. Losses

Like the roadway, the pickup elements have a relatively high $Q$. Thus, the separate determination of losses of each element by power, current, and voltage measurements was not possible. And, again, the bridge measurements were at either $100 \mathrm{~Hz}$ or $1000 \mathrm{~Hz}$ with the problem of interpolation for the operating frequency of $283 \mathrm{~Hz}$. As with the roadway, tests can be conducted at various values of tuning capacitance, $\mathrm{C} 2$, and this provides the means to determine the losses in C2, and, from this, the losses in the inductors, both mutual and leakage. That is, the mutual losses can be separated from the ESR for the leakage inductance because the mutual inductance varies considerably more than the leakage inductance as the airgap is changed.

The model of the pickup is more complicated than the roadway because of the two inductance losses, mutual and leakage. Furthermore, the pickup was tested with a set of capacitors that had been added in a temporary way and the wiring added an additional complication that was not immediately recognized. The temporary wiring was made with many strands of small bare wire, but apparently not enough of them as their loss contribution gave anomalous results until it was recognized. By adding another term to the mathematical model to account for the high loss wiring, the losses were decomposed into their separate parts in a reasonably accurate manner as is explained in the following section.

\section{Decomposition of the Pickup Losses}

In a manner similar to the roadway, the pickup losses were mathematically modeled initially by three terms:

$$
P=\left(V L 1^{2}\right) / R f+\left(L L 2^{2}\right) R L 2+\mathrm{dr}\left(V C 2^{2}\right) \omega C 2
$$

where $\quad$ P - power input to the pickup (W)

$$
\begin{aligned}
& \text { VL1 - voltage across the roadway, induced by the pickup (V) } \\
& \text { Rf - equivalent parallel resistor for core losses }(\tilde{\Omega}) \\
& \text { IL2 - current through the leakage inductance (A) } \\
& \text { RL2 - equivalent series resistance of the pickup windings } \\
& \text { df - dissipation factor of the pickup capacitance } \\
& \text { VC2 - voltage across C2 }(\mathrm{V}) \\
& \omega \text { - } 2 \pi f \text { and f is the frequency }(\mathrm{Hz}) \\
& \text { C2 - pickup tuning capacitance }(\mu \mathrm{F}) .
\end{aligned}
$$


This model did not fit the data very well, especially for the 8-cm gap which required the extra fixed capacitance with temporary wiring. Therefore, a fourth term was added to account for the higher resistance wiring:

$$
\mathrm{P}=\left(\mathrm{VL} 1^{2}\right) / \mathrm{Rf}+\left(\mathrm{IL2}^{2}\right) \mathrm{RL2}+\mathrm{df}\left(\mathrm{VC2} 2^{2}\right) \omega \mathrm{C2}+\mathrm{R} 2 \mathrm{R}(\mathrm{VC} 2 \omega \mathrm{C} 2 \mathrm{R})^{2}
$$

where R2R - extra resistance due to the temporary wiring $(\Omega)$

$C 2 R$ - the value of the extra capacitance $(\mu \mathrm{F})$.

Note that C2 is still the total capacitance and $\mathrm{df}$, the dissipation factor, is the total internal loss of $\mathrm{C} 2$ whereas $\mathrm{R} 2 \mathrm{R}$ is the wiring loss of only the temporary part of C2 that was needed to achieve resonance with the 8-cm gap. When the temporary wiring condition is corrected, the fourth term of Eq. (6) will not be needed.

Figure 4 is a plot of input power to the pickup (directly driven from the generator) as a function of the tuning capacitor, $\mathrm{C2}$, for 1-, 3-, 5-, and 8-cm gaps. As mentioned previously, the $8-\mathrm{cm}$ gap had such a low mutual inductance, LM, that $\mathrm{C2}$ had to be augmented with a fixed capacitance of $353 \mathrm{uF}$ in order to achieve resonance. In Fig. 5, the curves of Fig. 4 are repeated together with curves of the least-squares model of the data. The straight lines are model results and the coefficients of the model are:

$$
\begin{aligned}
\mathrm{Rf} & =6.073 \Omega \\
\mathrm{RL2} & =80.28 \mu \Omega \\
\mathrm{df} & =0.017 \\
\mathrm{R} 2 \mathrm{R} & =396.1 \mu \Omega \\
\mathbf{f} & =283 \mathrm{~Hz} .
\end{aligned}
$$

Because the core loss is a function of flux density which is a proportional to VM, it appears simpler to use an equivalent parallel resistor (EPR) rather than an ESR. Thus, Rf is represented as an EPR in Eq. (5) and (6). If the ESR form is used, its value will depend on the value of mutual inductance, LM. That is, the series equivalent impedance of the parallel combination of $\mathrm{Rf}$ and LM depends upon the reactance of LM and, therefore, the frequency, $\mathrm{f}$, as well as the value of $\mathrm{Rf}$. The value of $\mathrm{RC2}$ also depends upon $\mathrm{C2}$ and $\mathrm{df}$ such that

$$
\mathrm{RC2}=\mathrm{df} / \omega \mathrm{C2}
$$

and RC2 should be determined af ter the value of C2 has been established. 


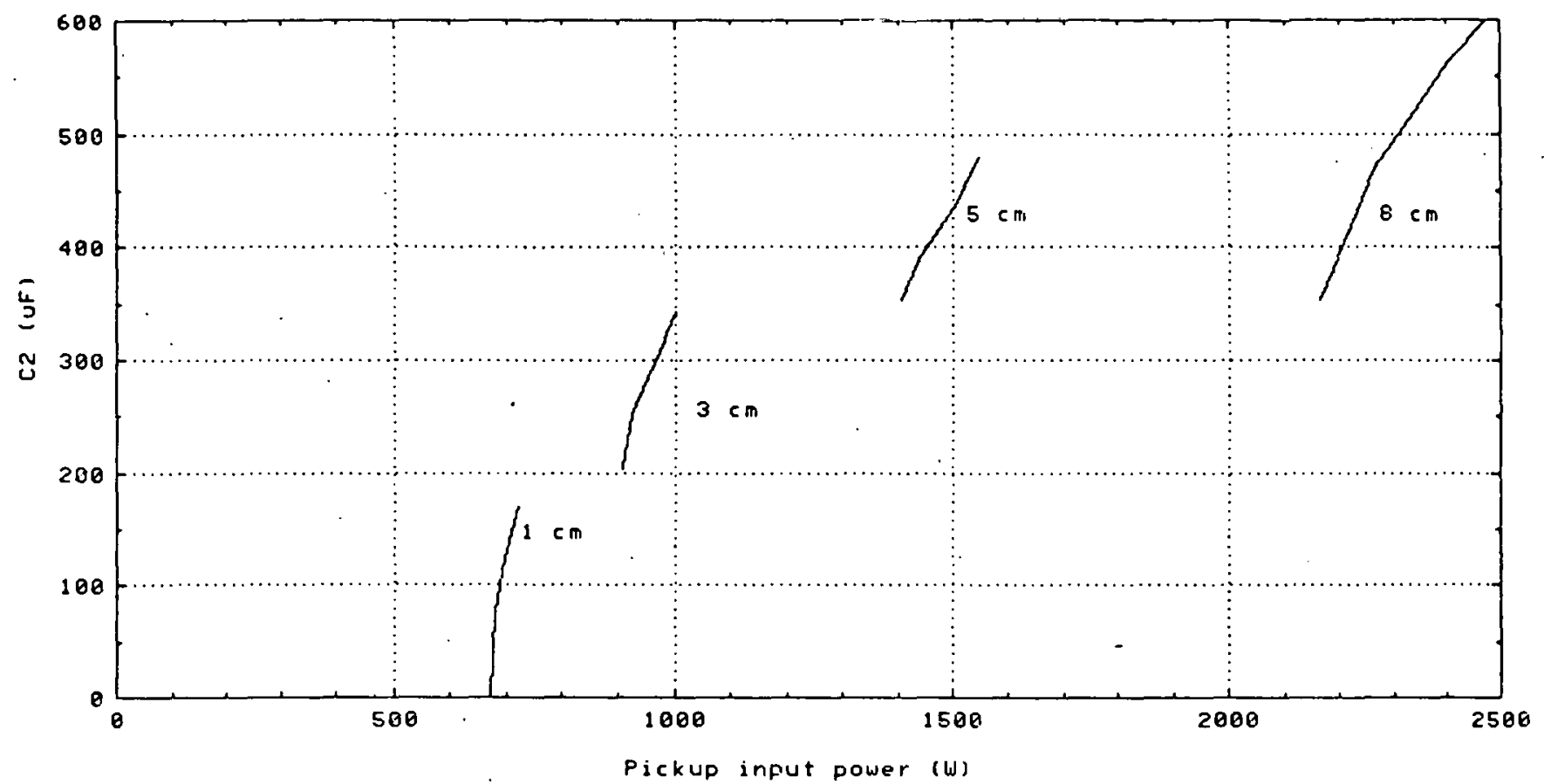

Fig. 4. Plot of tuning capacitance, C2, for various gaps as shown, as a function of input power to the STl pickup.

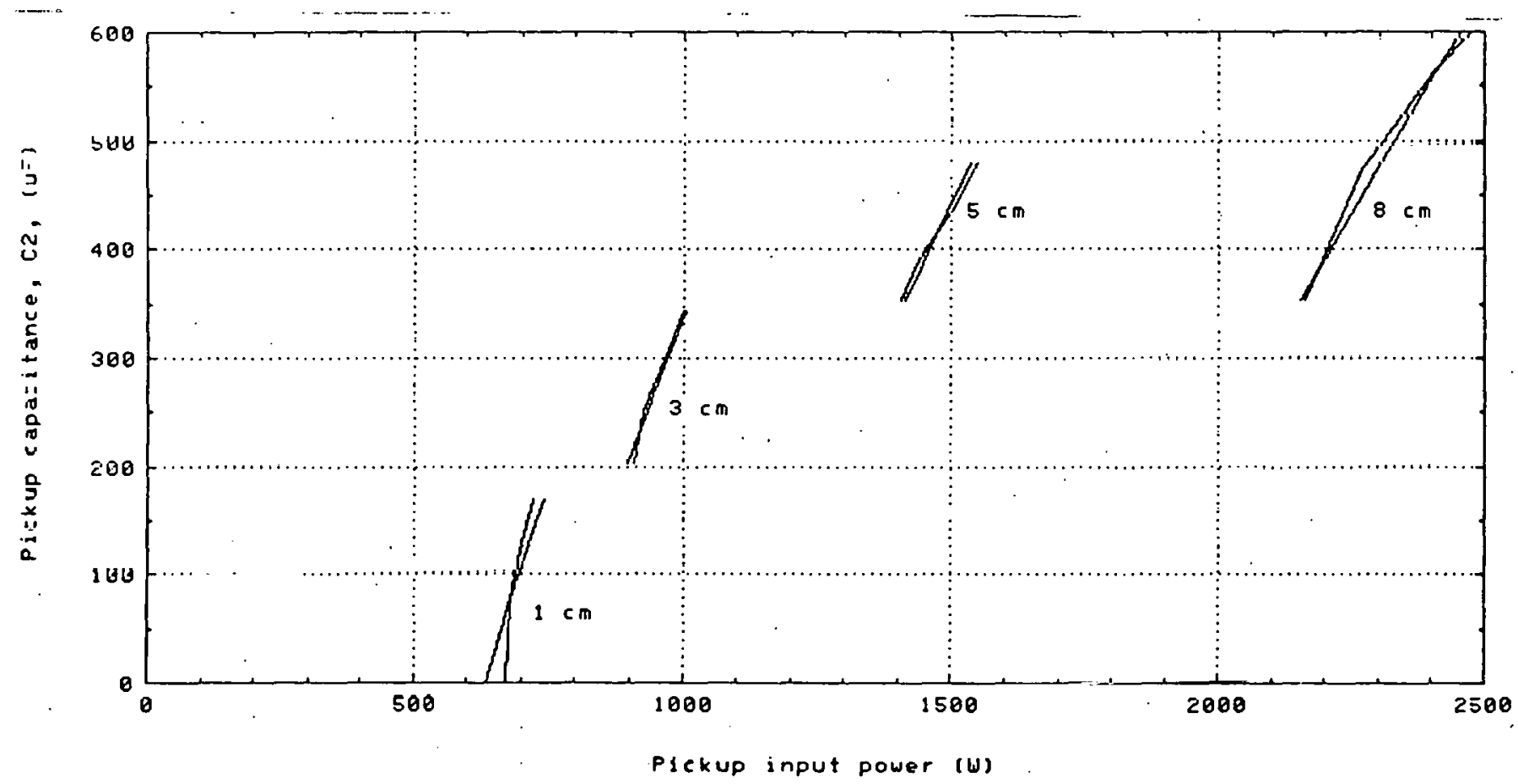

Fig. 5. Repeat of Fig. 4 but with a least-squares fit of the data superimposed on the original plot. The model for the fit was Eq. (6) and the straight-line plots are the results of this fit. 
The previous model results of the test data are compared with Ref. 1 model data as follows:

$\begin{array}{lcc} & \begin{array}{c}\text { Least-Squares } \\ \text { Test Data }\end{array} & \begin{array}{c}\text { Model of } \\ \text { Ref. 1 }\end{array} \\ \text { Rf }(\Omega) & 6.07 & 0.698 \\ \text { RM }(\mu \Omega) & 15.9 & 174.0 \\ \text { LM }(\mu \mathrm{H}) & 5.53 & 6.2 \\ \text { RL2 }(\mu \Omega) & 80.28 & 190.7 \\ \text { df }(-) & 0.017 & 0.001 \\ \text { R2R }(\mu \Omega) & 396.1 & 0.0 \\ \text { f }(\mathrm{Hz}) & 283.0 & 300.0\end{array}$

The experimentally determined ESR for core loss, RM, is ten times less than the value used in the Ref. 1 model. However, the experimentally determined capacitor losses, df; are seventeen times greater than in the Ref. 1 model. Note also that the 'pickup winding ESR is less than half the value used in the Ref. 1 model. R2R does not exist in the reference model.

Because the test data model gives such a large value for df (0.017) compared with Ref. 1 (0.001), the capacitor chassis for the vehicle should be examined and perhaps bridged in order to determine what is causing these high capacitive losses.

\section{MUTUAL AND LEAKAGE INDUCTANCE}

\section{Mutual Inductance Determination}

The mutual inductance between the roadway and pickup cores depends on the airgap between them. The value of this inductance, LM, is determined by measuring the volts-per-turn in any one of the windings of the pickup for a given amount of road current, ILl. This is expressed mathematically by:

$$
V / t=j \omega L M(I L l)
$$

or

$$
L M=(V / t) / j \omega(I L l)
$$

where $V / t$ - volts-per-turn ratio of the pickup winding (V)

j - the complex operator

$\omega$ - radian frequency $(1 / s)$

ILl - road current (A). 
Data for determination of the mutual inductance were taken in Test 16 and a plot of these data as a function of the airgap is given in Fig. 6. In Fig. 7, mutual inductance of the static pickup is shown again, but in this case, it was independently derived from the data of Test 22 which was a test to determine pickup losses. In this case, voltage was induced in the roadway by the current in the pickup winding. Fig. 7 is a plot of the least-squares fit of the data and Hoerl's equation was used as the model for this fit. When Fig. 7 was superimposed upon Fig. 6, it was found to be a very close.fit to the data points thus verifying the data of Test 16 .

\section{Leakage Inductance Determination}

'I'est 22 includes data for determination of the leakage inductance, L2, of the pickup used in the static tests. In order to determine L2, the load or reactance winding (series or parallel as long as the number of eff ective turns were taken into account) was shorted and the short-circuit current was measured for various gaps and a given road current. The rationale of this determination is that, on a one-to-one turns ratio such as the equivalent circuit, the road current, ILl, flows through the parallel combination of the mutual inductance, LM, and the leakage inductance, L2, and their loss resistors. But the current

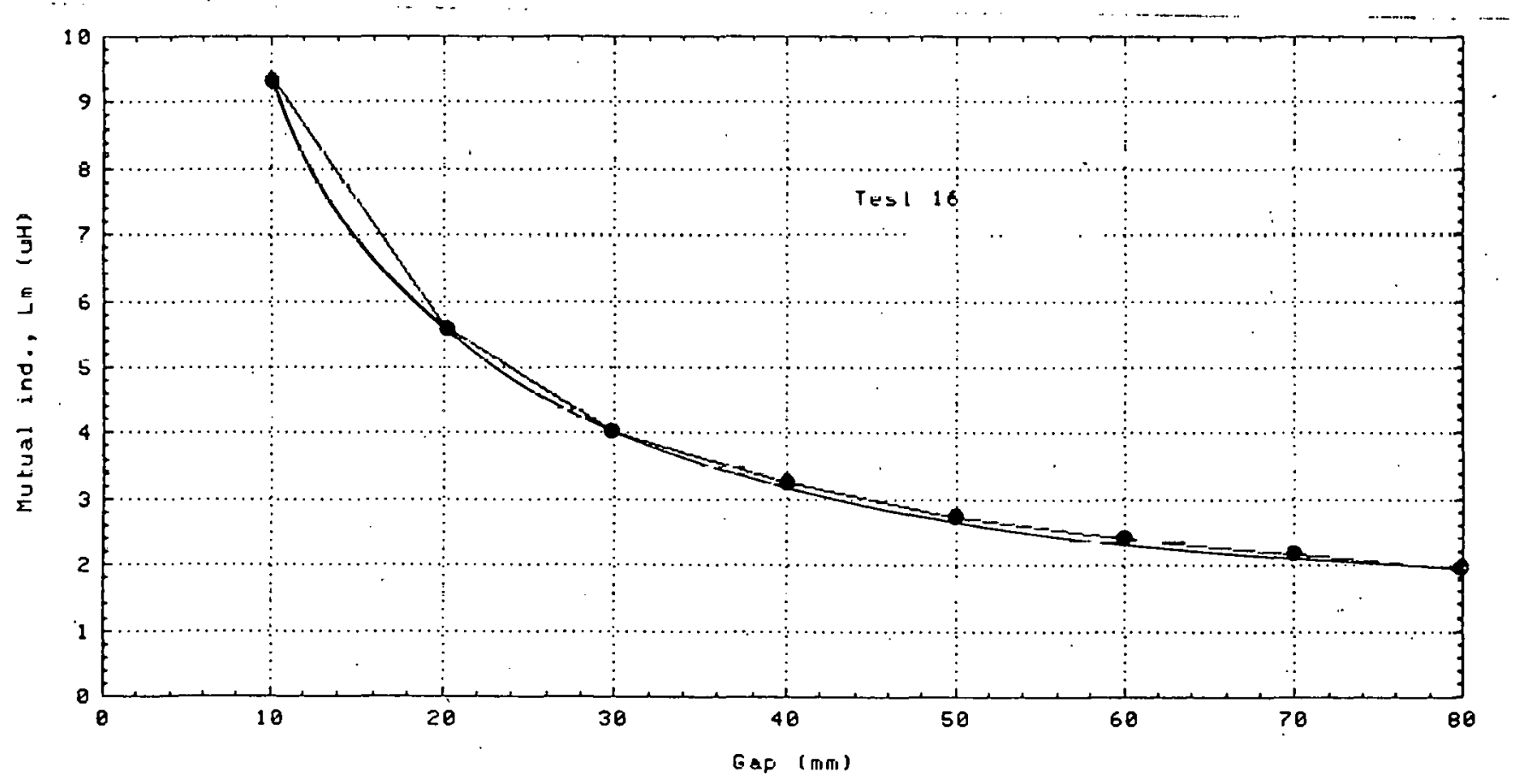

Fig. 6. Mutual inductance between the roadway core sections and the pickup used in static tests as a function of gap spacing. The data of Test 16 were used to derive these values of mutual inductance, LM. The straight line sections connect the original data and a French curve was used to draw the curved line through the data points. 
that flows in each leg is dominated by the inductance so, to a close approximation, the road current divides according to the reciprocal values of LM and L2. That is,

$$
\mathrm{LL}=(\mathrm{VM} / \omega)(1 / \mathrm{LM}+1 / \mathrm{L} 2)
$$

and

$$
\mathrm{VM} / \omega=(\mathrm{II} 2)(\mathrm{L} 2)
$$

where VM - voltage across the mutual inductance and, in this case, L2 as well IL2 - short-circuit current of the winding multiplied by the number of turns of the winding.

Once LM is determined, the only unknown in Eq. (10) is L2. A plot of the calculated values of $\mathrm{L} 2$ is shown in Fig. 8.

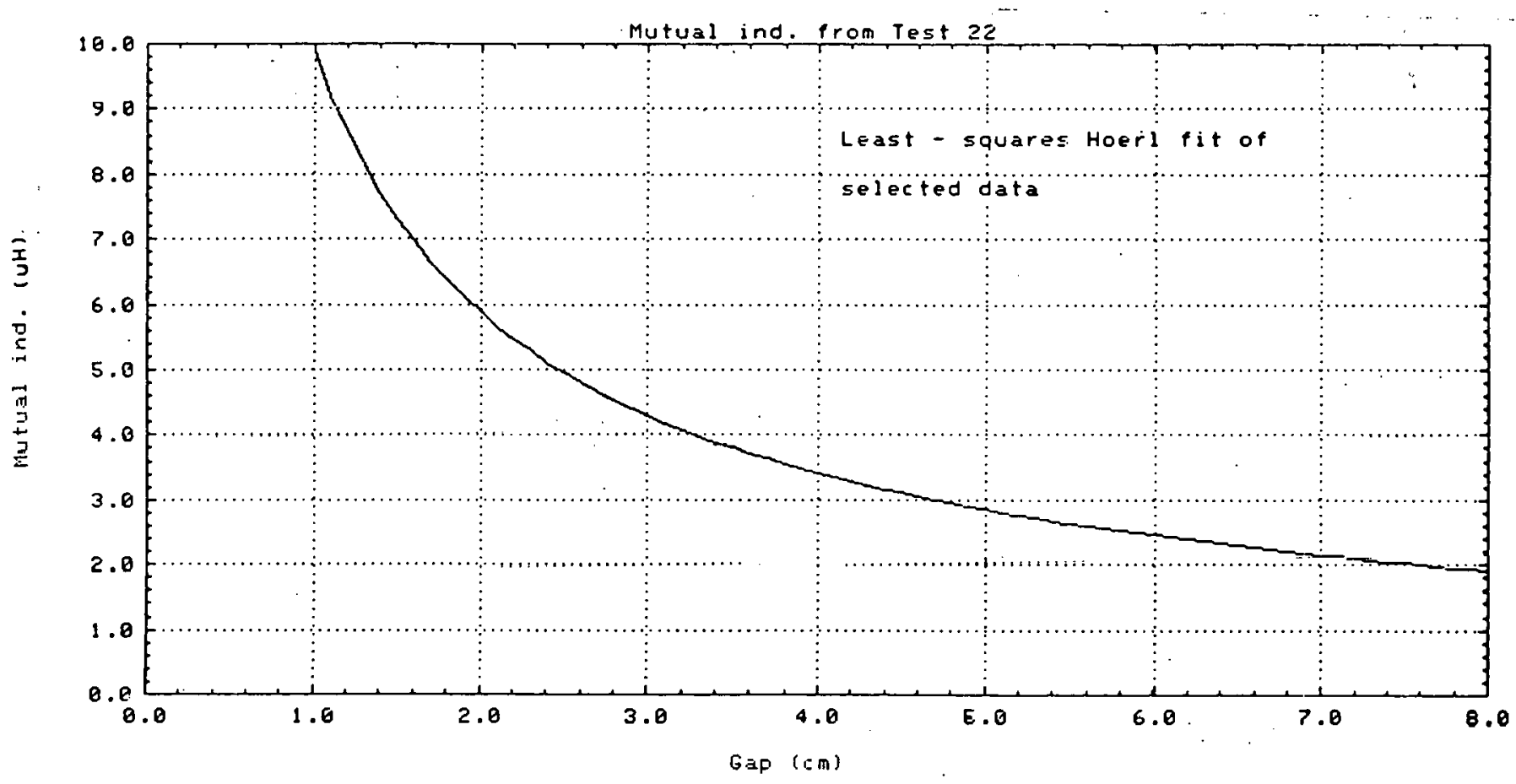

Fig. 7. Least-squares plot of mutual inductance, LM, as derived from the the data of Test 22. The model for this plot was the Hoerl equation. This plot fits the data of Fig. 6 very closely and verifies the accuracy of these data. Test 22 was a test to derive pickup losses and the mutual inductance data was a byproduct of this test. In this case, the voltage was induced in the roadway. 


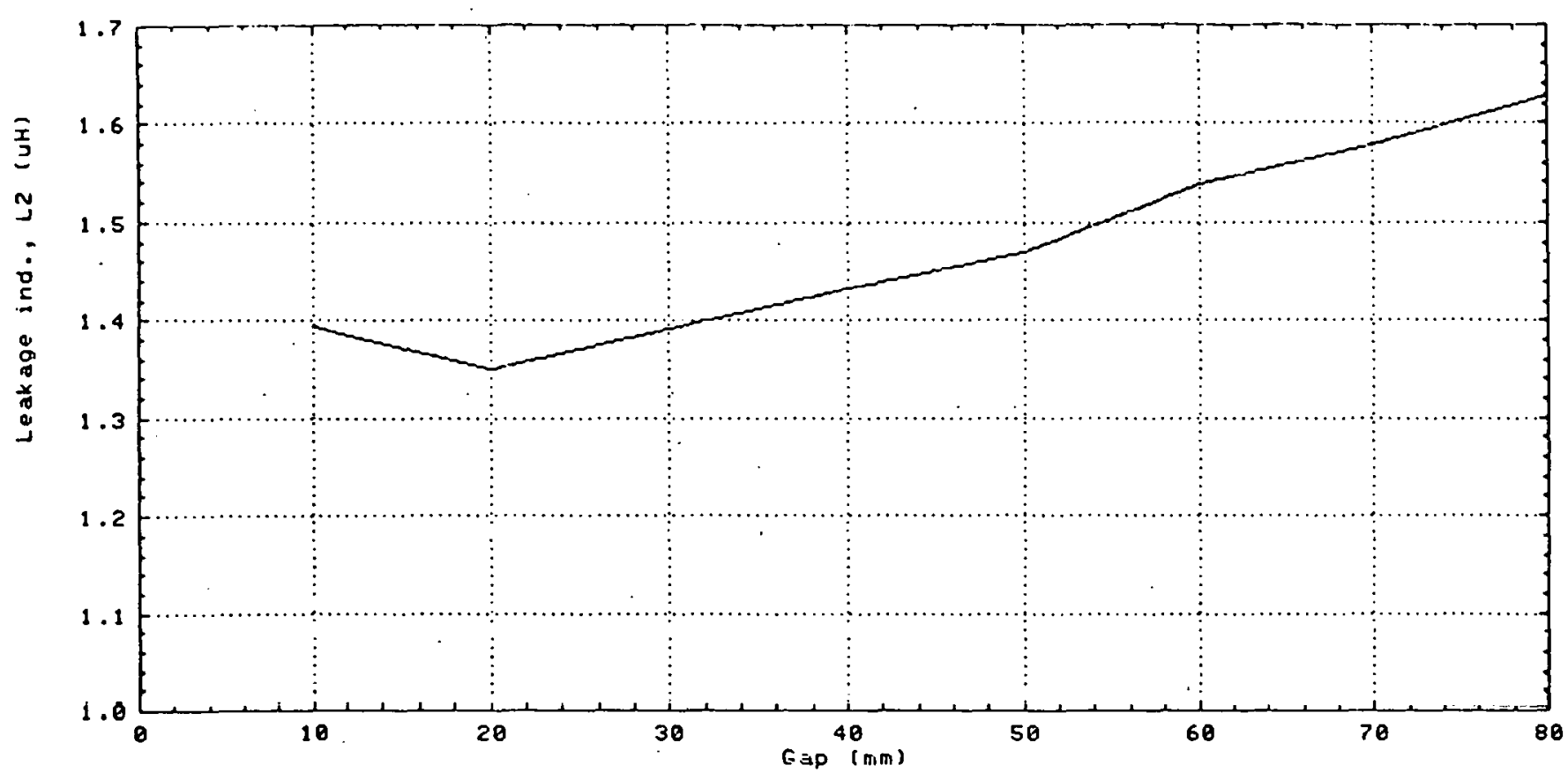

Fig. 8. Leakage inductance, L2, of the static pickup as a function of airgap. The data of Test 16 were used to derive the values of $L 2$.

\section{REFERENCES}

1. J. D. Salisbury and C. E. Walter, "Projected Electrical Characteristics of the Dynamic RPEV System," September 1981, Lawrence Livermore National Laboratory, UCID $1 \mathrm{gIRR.}$ 


\section{INSTRUMENTS}

1. Clip-on ac Power Meter, Model 2433, DOE 264732 (Mfg: Yokogawa Electric Works)

As the name describes, this is a clamp-on (clip-on) meter for measuring power, voltage, and current. It measures true rms voltage, current, and power from $40 \mathrm{~Hz}$ to $400 \mathrm{~Hz}$ and displays the result in digital form with an LCD display.

Ranges (rms): $200 / 600 \mathrm{~V}, 20 / 200 \mathrm{~A}, 20 / 200 \mathrm{~kW}$

2. Volt-Ampere-Watt Meter, Model 620, DOE 264923

(Mfg: RFL Industries, Inc.)

This is also an rms meter like the YEW Mod. 2433, but it measures current directly or through an external current transformer (Weston 327 or equivalent). In the direct connection, the maximum current input is $20 \mathrm{~A}$ in eight steps and the maximum voltage input is $600 \mathrm{~V}$ in five steps. For currents higher than $20 \mathrm{~A}$, a current transformer of suitable ratings can be used and the power and current readings can be converted to actual values by multiplying the readings by the current-transformer ratio.

Ranges (rms): $30 / 60 / 150 / 300 / 600 \mathrm{~V}, 0.1 / 0.2 / 0.5 / 1 / 2 / 5 / 10 / 20 \mathrm{~A}, 3 \mathrm{~W}$ to $12 \mathrm{~kW}$

3. Digital Multimeter, Model RMS 3030, DOE 00314319

(Mfg: Beckman)

We have two of these instruments at the dynamic test facility, but this one (DOE 00314319) gave $\mathrm{mV}$ readings from a current shunt that agreed well with RFL current readings. At present, this instrument is taped to the instrument rack and reads road current from a $1000 \mathrm{~A}, 50 \mathrm{mV}$ shunt.

4. Digital LCR Meter, Model 4262A, DOE 264497

(Mfg: Hewlett-Packard)

This is a digital impedance meter with a LED display that is hard to read in bright sunlight. Other than this deficiency, which can be avoided by adequate 
shading, the instrument is the best available to our knowledge and provides ease of using with apparent high accuracy. The only reservations we have with the use of it on the dynamic RPEV system components are that it appears to be more of a laboratory than field instrument, cannot be used with either side of the component grounded to earth, and has about 18-inch long clip leads for connecting to the unknown. On the last mentioned point, the inductance of the leads when shorted together is only $0.8 \mathrm{uH}$ at $1000 \mathrm{~Hz}$ whereas the road inductance is $114 \mathrm{uH}$. So this is on the order of $1 \%$ for the measurement error if not taken into consideration. And it would similarly affect capacitance measurements.

This meter offers a choice of three operating frequencies: $100 \mathrm{~Hz}, 1 \mathrm{kHz}$, and $10 \mathrm{kHz}$. Note that this instrument has been modified by the manufacturer to operate at $100 \mathrm{~Hz}$ on the "120 Hz" selection. This is a standard option.

The HP meter has a very broad range capability and can measure $10 \mathrm{mF}$ $(10,000 \mathrm{uF})$ at $100 \mathrm{~Hz}$. It has a complicated (but versatile) front panel that becomes simple to interpret once the user get familiar with it.

Ranges: (See meter front panel or the operating and service manual)

5. Digital İmpedance Meter, Model 251, ERDA 222697 (Mfg: Electro Scientific Industries, Inc.)

This is similar to the HP LCR meter except that it has one operating frequency, $1 \mathrm{kH}$, and does not have the broad range of the HP meter. For example, the maximum value of capacitance that it can measure is $200 \mathrm{uF}$ whereas the HP meter can measure $10 \mathrm{mF}(10,000 \mathrm{uF})$ at $100 \mathrm{~Hz}$.

It was used prinurlly as a means of verlfying results. It is also somewhat lighter and simpler to use than the HP meter. 


\begin{abstract}
APPENDIX
The data described here were taken to make an initial characterization of the dynamic RPEV system. At the time these data were taken, the automatic data acquisition system was not yet available for use, therefore, the data was taken with the system in the static mode only. Brief description of the tests conducted to date are given below. Test data are recorded in the RPEV Test log book in Bldg. 6951.
\end{abstract}

\title{
Description of Tests
}

Test 1. AC Measurements on (DT-1) Pickup Windings

Measurements were made on the unmounted dynamic pickup windings with the HP $4262 \mathrm{~A}$ and ESI 251 bridges to determine the equivalent loss resistance, ESR, of these coils. Tests 2-7 inclusive were also conducted in order to characterize these coils.

Test 2. AC Measurements on Pickup Coils (no Core) (Wattmeter Meas.)

ESR was derived for the DT-1 pickup windings by means of power, voltage, and current measurements.

Test 3. AC Measurements on Pickup Coils (Blue Coil \#2) (no Core)

Same measurements as previous test which was on the White coil \#1.

Test 4. Temperature Rate-of-Rise Derivation of ESR (\#2 Coil)

In this experiment, ESR was calculated from the initial rate-of-rise of the temperature of the windings when heated by a given input electrical power.

Test 5. Temperature Rate-of-Rise for \#1 Coil

Same experiment as previous except with the windings on Coil \#1. 
Test 6. AC Resistance of Reactance Winding

Tests 4 and 5 were repeated in this test which used a hollowed out block of styrofoam for thermal insulation.

Test 7. LCR Bridge (ESI 251) Measurements on \# 1 Coil

Bridge measurements were repeated on Coil \#l using the ESI 251 bridge.

Test 8. Inductance Measurements on Roadway Conductors

The inductance of individual conductors of the roadway were measured by both impedance bridges. The total inductance (all conductors strapped together at each end) was also measured.

Test 9. Inductance Measurements of Roadway Conductors Incl. Mutual

Each conductor was measured in series with the rest of the conductors strapped together. This was done in both a series-aiding and series-opposing arrangement. Both bridges were used.

Test 10. First Turn on w/Vehicle 4:10 pm (Static Pickup)

This was a roadway conductor current balance test.

Test 11. Max. Power Test at $2.7 \mathrm{~cm}$ Gap

Test 12. Roadway Cond. Current Balancing

Relative placement of the return conductoris was found to be an easy way to balance the conductor currents. This is based on the change in mutual inductance of a conductor as it is moved closer to or farther from the other conductors. Moving a conductor closer to other conductors increases its mutual inductance and therefore reduces its share of the total current. But it also interacts with the closer conductors and affects their current also. So the adjustment process is a little tricky and would be facilitated by the use of continuous individual current indications. 
Test 13. Motor Powered Directly from Rectifier - No Controller or Battery

By the time this test was run, a filter inductor was used in series with the rectifier output. The inductor was more for load conditioning than filtering and it isolated the pickup from the poor load quality of the motor (or battery).

The tests indicated that with the load windings in parallel, the acceleration of the vehicle was better than the series connection.

Test 14. Max. Power Transfer at a Given Road Current

A load power of $11.4 \mathrm{~kW}$ was achieved at a road current of $900 \mathrm{~A}$.

Test 15. Power Loss in Roadway

(This test was repeated and more data were taken in Test 24.)

Test 16. Mutual Inductance and Leakage Ind. vs Air Gap

Mutual inductance was obtained by open-circuit voltage measurements of the power windings with $900 \mathrm{~A}$ in the road conductors. This was done for various gaps and, at each gap, leakage inductance was determined by short-circuit current measurements of the windings. Either winding, power or reactance could be used for these data.

Test 17. Mutual Inductance with Offse.t

The previous test was repeated (mutual-ind. part) for various offset distances -3 to $14 \mathrm{~cm}$.

Test 18. Power Loss in Pickup and Coupled Core (Static Pickup) no Offset

Power readings were taken with the YEW clamp-on meter, but the readings were too coarse (only one significant digit at the test power level) for satisfactory data.

(This test was redone more completely in Tests 21,22 , and 29.) 
Test 19. Reduction of Road Inductance - Initially $135 \mathrm{uH}$

Because we were running out of generator voltage, currents of $1000 \mathrm{~A}$ or better were difficult to generate, that is, the generator field current required was in excess of $2 \mathrm{~A}$ and the ouput voltage was flattening which is indicative of flux density that is approaching saturation. (Note that the generator output voltage is rated at $120 \mathrm{~V}$, but this is at $400 \mathrm{~Hz}$. It is single-phase connected to give twice this voltage.) Before reduction, the generator output required for $900 \mathrm{~A}$ in the road was about $230 \mathrm{~V}$. After the inductance was reduced (to about $114 \mathrm{uH}$ ) by moving the return conductors closer to the concrete roadway, a current of $1000 \mathrm{~A}$ could be achieved at a generator voltage of $190 \mathrm{~V}$.

Test 20. Power Transfer at Max. Syst. Eff.

Obtained an efficiency of $62.4 \%$ at a $2-\mathrm{cm}$ gap with the water-cooled load at a resistance setting of about $0.6 \mathrm{ohm}$. This is the value for maximum efficiency according to the analysis ${ }^{l}$ and variation about this value seemed to confirm that it was the right setting.

Test 21. Pickup Driven - Power Windings (in Series)

The power loss of the pickup (static) was measured at gap settings of $1,2,4,6$, and $8 \mathrm{~cm}$. No capacitance; C2, tuning.

(This test was repeated in Tests 22,23 , and 29.)

Test 22. Pickup Driven - Reactance Windings (in Parallel)

This is the s8me 88 Teet 31 excopt that the reactance windings were driven or cxelted dircetly by the generator and no capacitance, C2, tuning was used.

Test 23. Pickup Driven - React. Winding (in Parallel) - Off the Powered Roadway

The pickup was raised to maximum gap, about $8 \mathrm{~cm}$, and the vehicle was positioned over an unpowered section of the roadway between expansion joints. The purpose of this experiment was to get a loss figure for the pickup without coupling to roadway cores. 
Test 24. Roadway Losses - Inductance (Now $114 \mu_{i} \mathrm{H}$ ) - Conductors at Original Length

In Test 19 , the roadway inductance was reduced in order to get more current through the roadway conductors. The purpose of this test was to get loss data on the roadway with the newly configured return conductors.

The extra lengths of return conductors now trace out about a 10-foot narrow loop at the east end of the powered section. This extra conductor length should be removed because it probably contributes significant additional loss and inductance.

Test 25. Generator Voltage Drop for Longer Cables

Prior to moving the generator to its present location, west of Building 6951 , the power cables that were to connect it to the roadway conductors were measured for voltage drop at various currents. The resistance of the leads to the field of the generator was also measured. From these tests; it was concluded that the use of the planned cables would cause only a small and acceptable voltage drop. (Note that if tests are run that require maximum generator voltage at or near its rated maximum power, additional power conductors can be added as there is large amount of this conductor material available at Bldg. 6951.)

Test 26. Roadway Power Losses at Various Values of $\mathrm{Cl}$

$\mathrm{Cl}$, the roadway tuning capacitance, was varied by starting close to resonance and reducing $\mathrm{Cl}$ until the generator current reached about $190 \mathrm{~A}$. (It was fused for 200 A.) As $\mathrm{Cl}$ was reduced the roadway power losses were also reduced because of the reduced $\mathrm{Cl}$ losses. From the data, the total power can be decomposed into capacitance and inductance losses. The accuracy of this decomposition is limited by the fact that $\mathrm{Cl}$ can only be reduced about $40 \%$.

Test 27. Bridge Measurements of $\mathrm{Cl}$ Capacitors

In order to increase the accuracy of data available for decomposing the roadway loss, the individual and combincd capacitors that make up $\mathrm{Cl}$ were 
measured by an impedance bridge. That is, the nominal values of switchable and fixed capacitance were measured for actual values of capacitance in order to increase the accuracy of decomposition of the power-loss data.

Test 28. Bridge Measurements of Pickup (C2) Capacitors

These measurements were taken in order to increase the accuracy of decomposition of pickup power-loss data that is given in Test 29.

Test 29. Pickup Driven - Power Windings - Initial Resonance Then C2 Decreased

Data on input power to the pickup at various gaps in order to characterize the pickup losses for efficiency determination. This is somewhat more difficult to do than the roadway because there are three unknowns, mutual inductance loss, pickup conductor loss, and pickup capacitance loss, whereas the roadway loss model consists of two unknowns. 


\section{DISCLAIMER}

This document was prepared as an account of work sponsored by an agency of the U nited States Government. Neither the United States Government nor the University of California nor any of their employees, makes any warranty, express or implied, or assumes any legal liability or responsibility for the accuracy, completeness, or usefulness of any information, apparatus, product, or process disclosed, or represents that its use would not infringe privately owned rights. Reference herein to any specific commercial products, process, or service by trade name, trademark, manufacturer, or otherwise, does not necessarily constitute or imply its endorsement, recommendation, or favoring by the United States Government or the University of California. The views and opinions of authors expressed herein do not necessarily state or reflect those of the United States Government thereof, and shall not be used for advertising or product endorsement purposes.

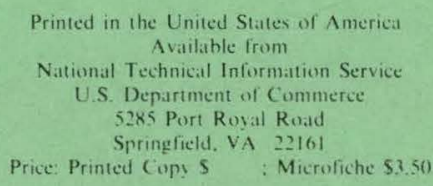

\begin{tabular}{|c|c|c|c|}
\hline Page Range & $\begin{array}{l}\text { Domestic } \\
\text { Price }\end{array}$ & Page Range & $\begin{array}{l}\text { Domestic } \\
\text { Price }\end{array}$ \\
\hline $001-025$ & $\$ 5.00$ & $326-350$ & $\$ 18.00$ \\
\hline $026-050$ & 6.00 & $351-375$ & 19.00 \\
\hline $051-075$ & 7.00 & $376-400$ & 20.00 \\
\hline $076-100$ & 8.00 & $401-425$ & 21.00 \\
\hline $101-125$ & 9.00 & $426-450$ & 22.00 \\
\hline $126-150$ & 10.00 & $451-475$ & 23.00 \\
\hline $151-175$ & 11.00 & $476-500$ & 24.00 \\
\hline $176-200$ & 12.00 & $501-525$ & 25.00 \\
\hline $201-225$ & 13.00 & $526-550$ & 26.00 \\
\hline $226-250$ & 14.00 & $551-525$ & 27.00 \\
\hline $251-275$ & 15.00 & $526-550$ & 28.00 \\
\hline $276-300$ & 16.00 & $601-$ up 1 & \\
\hline $301-325$ & 17.00 & & \\
\hline
\end{tabular}

${ }^{1}$ Add 2.00 for each additional 25 page increment from 601 pages up. 
Technical Information Department - Lawrence Livermore National Laboratory University of California - Livermore, California 94550

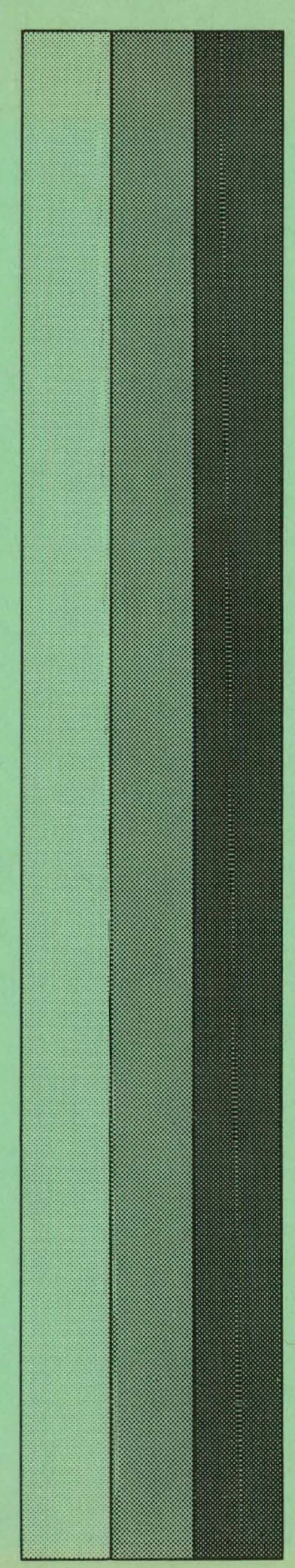

